\title{
Educação Especial, Educação Inclusiva e Pedagogia da Diversidade: celebrar a diversidade! Exaltar a tolerância! Notabilizar o respeito! Proclamar a solidariedade!
}

\author{
Márcia Lise Lunardi-Lazzarin* \\ Simoni Timm Hermes**
}

\section{Resumo}

$\mathrm{Na}$ articulação da Educação Especial com a Educação Inclusiva, este artigo objetiva problematizar como a Pedagogia da Diversidade tem perpassado a formação continuada das professoras e as práticas curriculares ditas inclusivas na escola contemporânea. A partir dos Estudos Foucaultianos em Educação e dos Estudos Culturais, a materialidade analítica constitui-se por relatos da obra "Atendimento Educacional Especializado no Brasil: relatos da experiência profissional de professores e sua formação", derivada do Curso de Aperfeiçoamento/Extensão em Atendimento Educacional Especializado, ofertado por uma universidade pública do sul do país, na Rede Nacional de Formação Continuada de Professores na Educação Especial. Nessa materialidade analítica, o direito à educação reveste-se como direito à educação da diversidade, e este direito potencializa as operaçóes do Atendimento Educacional Especializado na escola dita inclusiva. Nesse contexto, a Política Nacional de Educação Especial na Perspectiva da Educaçáo Inclusiva aciona o preparo para o acolhimento e o trato da diversidade, de modo a intensificar a formação continuada das professoras, em detrimento da formação inicial, e produzir a informação, a opinião, a generalização, a rapidez e o pragmatismo do atual serviço da Educaçáo Especial nesses cursos de aperfeiçoamento/extensão. Celebrar a diversidade! Exaltar a tolerância! Notabilizar o respeito! Proclamar a solidariedade! Por meio da tríade da tolerância, do respeito e da solidariedade, essa formação continuada e as práticas curriculares na escola dita inclusiva produzem modos de sociabilidade plurais, inclusivos no registro da governamentalidade neoliberal.

Palavras-chave: Educação especial; Educação inclusiva; Pedagogia da diversidade.

* Professora doutora da Universidade Federal de Santa Maria, Santa Maria, Rio Grande do Sul, Brasil.

** Doutoranda pela Universidade Federal de Santa Maria, Santa Maria, Rio Grande do Sul, Brasil. 


\section{Special Education, Inclusive Education and Pedagogy of Diversity: celebrating diversity! Exalting tolerance! Distinguishing respect! Preaching solidarity!}

\section{Abstract}

In the articulation between Special Education and Inclusive Education, this paper aims to problematize the way in which the Pedagogy of Diversity has impregnated teacher continuing education and curriculum practices taken as inclusive in the contemporary school. By considering the Foucauldian Educational Studies and Cultural Studies, the analytical materials consisted of reports from "Special Educational Assistance in Brazil: Reports of Teacher Professional Experience and Education", deriving from the refresher/extension course in Specialized Educational Assistance offered by a southern public university in the National Network of Continuing Education for Special Education Teachers. In that analytical materiality, the right to education is regarded as a right to diversity education, and this right potentializes the operations of the Specialized Educational Assistance in the so-called inclusive school. In this context, the National Special Education Policy from the Inclusive Education Perspective triggers the preparation for both receiving and handling diversity in order to intensify teacher continuing education rather than their initial education and produce information, opinion, generalization, promptness and pragmatism of the current Special Education service in those refresher/extension courses. Celebrating diversity! Exalting tolerance! Distinguishing respect! Preaching solidarity! By means of the tolerance, respect and solidarity triad, continuing education and curriculum practices of the so-called inclusive school have produced plural, inclusive modes of sociability under the domain of the neoliberal governmentality.

Keywords: Special education; Inclusive education; Pedagogy of diversity.

$\mathrm{Na}$ articulação da Educação Especial com a Educação Inclusiva, tomamos a diversidade como princípio para significar o caráter pretensamente natural e pluralista da sociedade contemporânea. Nesse contexto, através da Pedagogia da Diversidade, produzimos a escola como responsável pela produção de modos de sociabilidade ditos inclusivos. Do princípio à pedagogia, celebrar a diversidade! Ao pontuar a diferença, a educação e a cultura tematizadas neste dossiê, tratamos de acentuar a discursividade produtiva da Educação Especial, da Educação Inclusiva e da Pedagogia da Diversidade, seja pela formação continuada de professoras, seja pelas práticas curriculares ditas inclusivas na escola contemporânea, bem como de problematizar as formas colocadas em operação para ser e estar nessa escola.

Tal pressuposto de desnaturalização dos discursos e problematização das práticas, ao ser constituído no conjunto dos Estudos Foucaultianos em Educação e dos Estudos Culturais, materializa parte dos exercícios de problematização do projeto 
de pesquisa "A produção de práticas discursivas no campo da Educação Especial no contexto da racionalidade inclusiva", desenvolvido pelo Grupo de Pesquisa "Diferença, Educação e Cultura" vinculado ao Conselho Nacional de Desenvolvimento Científico e Tecnológico (CNPq), constituído por pesquisadoras da Universidade Federal de Santa Maria, Estado do Rio Grande do Sul, Brasil. Diante disso, neste artigo, objetivamos problematizar como a Pedagogia da Diversidade tem perpassado a formação continuada das professoras e as práticas curriculares ditas inclusivas na escola contemporânea.

Para tal, ocupamo-nos dos relatos da obra "Atendimento Educacional Especializado no Brasil: relatos da experiência profissional de professores e sua formação" (2014), inscrita no horizonte da Política Nacional de Educação Especial na Perspectiva da Educação Inclusiva e no conjunto das obras da Rede Nacional de Formação Continuada de Professores na Educação Especial. Esses relatos partilham a lógica da participação de professoras no Curso de Aperfeiçoamento/Extensão em Atendimento Educacional Especializado, ofertado por uma universidade pública do sul do país; da relação deste Curso com a prática profissional nas diversas regiôes brasileiras; e da indicação dos módulos mais importantes nessa relação. Por sua vez, recorrem nesses relatos o ideário do direito à educação e do direito à educaçáo da diversidade para produção da inclusão verdadeira.

Exaltar a tolerância! Notabilizar o respeito! Proclamar a solidariedade! Celebrar e pedagogizar a presença contínua e permanente da diversidade no cenário educacional! A partir das recorrências discursivas da materialidade analítica em questão, efetivamos o exercício de problematização em torno desses relatos, no sentido de, na evidência desses direitos, tensionar a zona de produtividade discursiva da Pedagogia da Diversidade no foco prioritário da articulação entre a Educação Especial e a Educação Inclusiva, ou seja, o Atendimento Educacional Especializado, serviço este responsável por complementar ou suplementar a formação dos alunos com deficiências, transtornos globais do desenvolvimento e altas habilidades/superdotação na escola comum/regular com a publicação da Política Nacional de Educação Especial atual.

\section{Direito à educação da diversidade}

\section{(ou celebrar a diversidade!)}

Para tanto, não irei me restringir apenas nesse curso, buscarei outras fontes de conhecimentos para realizar o meu trabalho da melhor forma possível e ajudar no processo de inclusão da pessoa com deficiência não apenas no ambiente escolar, mas sim na sociedade, onde não é a pessoa com deficiência que mais tem a ganhar, e sim a sociedade que ganhará mais com a diversidade. (COELHO, 2014, p. 110).

No contexto internacional, documentos como a Declaração dos Direitos das Pessoas Deficientes (Assembléia Geral da Organização das Naçóes Unidas, 1975), a Declaração Mundial sobre Educação para Todos (Conferência de Jomtien, Tailândia, 1990), a Declaração de Salamanca (Espanha, 1994) e a Convenção de Guatemala (República da Guatemala, 2001) consolidam o direito à educação a todo e qualquer 
sujeito. Da mesma forma, no domínio nacional, a Constituição Federal de 1988; o Estatuto da Criança e do Adolescente, Lei n. 8.069, de 13 de julho de 1990; e a Lei de Diretrizes e Bases da Educação Nacional, Lei n. 9394, de 22 de dezembro de 1996, ratificam esse direito, preferencialmente, na rede regular de ensino. Tais documentos legais potencializam a articulação entre a Educação Especial e a Educação Inclusiva na atualidade.

No conjunto desses documentos orientadores e legais, a Política Nacional de Educação Especial, publicada em 1994, colocava a Educação Especial como serviço que complementava ou suplementava a escola comum/regular, contudo, nos casos dos sujeitos com deficiência, condutas típicas e altas habilidades/superdotação com maior comprometimento, esse serviço poderia substituir essa escola. No movimento da inclusão como preferência, as professoras de Educação Especial acompanhavam e intervinham no processo de aprendizagem e desenvolvimento desses sujeitos na escola comum/regular ou nas demais modalidades de atendimento da Educaçáo Especial. O ideário de abandono ou superação da herança histórica de subsistema da Educação Básica possibilitou produzir a Educação Especial na transversalidade dos níveis e das etapas da Educação Nacional.

Como reforça o fragmento do relato "AEE para o autismo infantil", utilizado na epígrafe desta seção, entre ganhos e perdas, tendemos a ganhar com a inclusão dos alunos com deficiência não apenas na escola, mas na sociedade como um todo. A transversalidade da Educação Especial na Educação Básica e Superior intensificou-se nas duas últimas décadas, principalmente, com a publicação da Política Nacional de Educação Especial na Perspectiva da Educaçáo Inclusiva em 2008, na medida em que a Educação Especial passou a integrar a proposta pedagógica da escola regular. Náo se trata, como outrora, de tomar a Educação Especial como um apêndice dessa escolarização regular, mas como modalidade integrante desta. Entre ganhos e perdas, a escola comum/regular ganhou com a diversidade do público-alvo da Educação Especial, e vice-versa.

Então, a partir da Política Nacional em questão, essa escola comum/regular tornou-se o lugar da aprendizagem e do desenvolvimento dos sujeitos da Educação Especial (sujeitos com deficiência, transtornos globais do desenvolvimento e altas habilidades/superdotação), independente dos graus de comprometimento desses sujeitos, pois eles têm à disposição o serviço do AEE ofertado no contraturno da escolarização. Esse serviço do AEE complementa ou suplementa a formação do público-alvo da Educação Especial através de atividades, recursos e profissionais - neste caso, as professoras do AEE e demais envolvidos - nas salas de recursos multifuncionais, dotadas de equipamentos de informática, mobiliário, materiais didático-pedagógicos e de acessibilidade, e nos demais espaços-tempos da escola comum/regular.

Nesse sentido, entendemos que a política de inclusão é clara na especificação dos alunos que recebem o AEE nas escolas comuns e, portanto, têm sua matrícula computada no ensino regular e no atendimento. (KARSTEDT, 2014, p. 91).

Considerando o fragmento do relato "Aplicabilidade do Curso AEE: desenvolvimento da autonomia”, a Educação Especial e a Educação Inclusiva acabam sen- 
do tomadas como sinônimas nos discursos da maioria das professoras. Talvez porque, desde 2011, a Educação Especial esteja hierárquica e funcionalmente na Secretaria de Educação Continuada, Alfabetização, Diversidade e Inclusão. Talvez porque a Política Nacional, ao orientar as açôes da Educação Especial, inscreva-a na perspectiva da Educação Inclusiva. Talvez porque as açôes de Educação Inclusiva em nosso país estejam sob responsabilidade da própria Educação Especial. Elegidos esses motivos entre outros possíveis para justificar a semelhança entre essas noções, firmamos, mais uma vez, que Educação Especial e Educação Inclusiva não significam a mesma coisa.

A Educaçáo Especial, junto ao sistema de expertise - como a Medicina Social, a Psicologia e a Pedagogia -, constituiu-se historicamente como campo de saber e poder capaz de discursivamente produzir os sujeitos com deficiência, transtornos globais do desenvolvimento e altas habilidades/superdotação, bem como possibilitar açôes institucionais voltadas a esse público-alvo. A Educação Inclusiva, embora se volte a esses sujeitos, trata do direito à educação de outras minorias sociais. A Educação Inclusiva engloba o serviço da Educação Especial na escola comum/regular e, sendo o AEE o serviço produzido nessa articulação, a Educação Especial não desaparece, mas potencializa o sucesso do movimento da inclusão obrigatória na escola. Por isso, essas noçôes não são sinônimas, mas compóem-se reciprocamente no cenário contemporâneo.

Nesse contexto, o direito à educação reveste-se como direito à educação da diversidade, e este direito potencializa as operaçôes do AEE na escola dita inclusiva. Cada um e todos têm direito à educação e, nestas duas últimas décadas, o direito à educação escolar no sistema regular de ensino. Com isso, a diversidade envolve unidades diversas num mesmo propósito, neste artigo, a inclusão escolar obrigatória. Náo se trata, portanto, de tomar diferença e diversidade na sinonímia. A diversidade relaciona-se com a identidade referencial e a pluralidade; a diferença, no sentido deleuziano, simplesmente difere. Vejamos, respectivamente, os fragmentos dos relatos "Relato 24 - Aplicabilidade do Curso de AEE: o movimento da Educação Inclusiva" e "Relato 4 - Inclusão escolar - A vez das diferenças":

Trata-se, portanto, de duas questóes - o direito à educação, comum
a todas as pessoas, e o direito de receber essa educação sempre que
possível com as demais pessoas nas escolas regulares. (OLIVEIRA,
2014, p. 167).
Cabe destacar que os conhecimentos construídos por meio do
Curso possibilitaram a continuidade das minhas açóes pedagó-
gicas, pautadas em uma prática inclusiva mais coente para os
profissionais permanecerem sensibilizados e abertos à diversidade
que demanda as escolas, dentro de uma perspectiva que promova
o desenvolvimento educacional, tendo em vista discussóes contí-
nuas em meu contexto de trabalho. (GONÇALVES, 2014, p. 41).

No primeiro fragmento, o direito à educação, que como direito social seria comum a todos os sujeitos, reveste-se como direito à educação da diversidade, na medida em que se trata de trazer os sujeitos da diversidade ao local próprio para a escolarização. Direito e diversidade reforçam-se, sendo que o direito à educação pos- 
sibilita celebrar a diversidade e, por sua vez, a diversidade faz recuperar esse direito de estar junto com os outros na escola contemporânea. Direito e diversidade tornam-se condiçóes de possibilidade para o movimento de inclusão obrigatória na escola. No segundo fragmento, a prática inclusiva mais coerente materializa-se pelo potencial de abertura e sensibilização diante desse outro, e impulsiona-nos a problematizar a formação continuada dessas professoras no AEE como possibilidade dessa prática inclusiva na atualidade.

$\mathrm{Na}$ área da Educação Especial e da Educação Inclusiva fiz vários cursos, entre eles destaco:

- Formação Continuada em Educação Inclusiva - 40hla;

- Formação Continuada em Educ. Inclusiva -Tecnologia Assistiva - 40/horas;

- Curso de Orientaçôes Básicas para o Funcionamento da Sala de Recursos Multifuncionais - 40/horas;

- Curso de Formação para Professores em Serviço de Informática na Educação Especial (6a Edição /II Semestre) - UFRGS, 120/horas;

- Curso de Extensão em Atendimento Educacional Especializado- AEE, 220/horas.

- Curso de Inclusão e Mobilidade Reduzida - 20/ horas.

- Atualmente cursando:

- Formaçöes LIBRAS -80/horas (presencial)

- Curso de Formação Continuada de Professores em Tecnologias de Informática e Comunicação Acessiveis -215/horas (TelEduc) (SANTOS, 2014, p. 141-142).

Esse fragmento, retirado do relato "Curso AEE: viabilizando o trabalho em equipe", evidencia a rede de investimentos massivos no nível da docência para garantir o sucesso da inclusão escolar do público-alvo da Educação Especial. Por isso, estão presentes no relato desde cursos voltados à Educação Inclusiva, lida aqui como princípio, política e prática que engloba o serviço da Educação Especial, mas não se reduz nele; ao AEE; à acessibilidade; às orientaçôes para a sala de recursos multifuncionais; à Língua Brasileira de Sinais; à condição de mobilidade reduzida; à informática na Educação Especial; à Tecnologia Assistiva, entre outros. Dito de outra maneira, esses cursos mostram a inclusão como uma verdade na escola contemporânea.

E, sendo uma verdade, torna-se imprescindível investir na lógica do menos como mais, própria da governamentalidade neoliberal presente no nosso país, para que as professoras dessas escolas sintam-se motivadas - "a motivação para a aprendizagem dos alunos matriculados" (SILUK, PAVÃO, 2014, p. 24) referenda um dos aspectos dos relatos que compóem a materialidade analítica - e preparadas para produzir práticas curriculares inclusivas. Então, a Política Nacional atual e essas práticas curriculares são gestadas pelo princípio de custo mínimo nesse Estado de governo 
que trabalha a serviço da economia. Nessa governamentalidade neoliberal, inclusive as relaçôes são mercantilizadas (FOUCAULT, 2008a, 2008b). Tudo e todos somos alvos e efeitos do Estado e do mercado, na medida em que nos constituímos e produzimos os outros como sujeitos econômicos.

Nesse contexto, parece que seja mais viável e retornável para o Estado brasileiro investir na formação continuada em detrimento da formação inicial, privilegiando o AEE como serviço em detrimento da Educação Especial como modalidade. Aliás, a pedagogia das competências, a prática profissional e a modalidade de educação a distância, presentes nessa formaçáo continuada, agregam capital humano às professoras para tornarem-se dinâmicas, flexíveis, um misto de polivalência e especialidade, e solidárias na escola dita inclusiva. Neste momento, a racionalidade política em questão mostra sua estratégia e suas táticas no comando das condutas docentes. Recuperamos dois artigos, respectivamente, o parágrafo $5^{\circ}$ do artigo $2^{\circ}$ da Resolução CNE/CP n. 2, de 01 de junho de 2015, e o artigo 18 da Resolução CNE/CEB n. 2, de 11 de setembro de 2001.

Art. 20 $\$ 5^{\circ}$ São princípios da Formação de Profissionais do Magistério da Educação Básica: II - a formação dos profissionais do magistério (formadores e estudantes) como compromisso com projeto social, político e ético que contribua para a consolidação de uma nação soberana, democrática, justa, inclusiva e que promova a emancipação dos indivíduos e grupos sociais, atenta ao reconhecimento e à valorização da diversidade e, portanto, contrária a toda forma de discriminação. (BRASIL, 2015).

Art. 18. Cabe aos sistemas de ensino estabelecer normas para o funcionamento de suas escolas, a fim de que essas tenham as suficientes condiçóes para elaborar seu projeto pedagógico e possam contar com professores capacitados e especializados [...]. (BRASIL, 2001).

No artigo 2, concernente às Diretrizes Curriculares Nacionais para a Formação Inicial em Nível Superior (cursos de licenciatura, cursos de formação pedagógica para graduados e cursos de segunda licenciatura) e para a Formaçấo Continuada, sinaliza-se que a formação para a docência deva reconhecer e valorizar a diversidade. Esse reconhecimento e essa valorizaçáo fazem do sujeito da diversidade esse outro "desde sempre aî" ou "para sempre aî", e da formação para a docência a maneira mais viável e retornável para o Estado Brasileiro garantir a gerência do risco dessa diversidade. Dito de outra maneira, parte-se do princípio de que esse outro exista como um a priori, e que as professoras devam reconhecê-lo na condição de outro e valorizar esse outro "desde sempre aî" ou "para sempre aî" no processo de escolarização.

$\mathrm{Na}$ continuidade dos documentos legais, o artigo 18, referente às Diretrizes Curriculares Nacionais para a Educação Especial na Educação Básica, postula o exercício das professoras capacitadas e das professoras especializadas nos sistemas de ensino. As professoras capacitadas comprovam, em sua formação no nível médio ou superior, os conteúdos da Educação Especial, na maioria das vezes, presentes na proliferação de disciplinas sobre a Educação Especial e seu público-alvo na formação 
inicial ou nesses cursos de aperfeiçoamento/extensão na formação continuada. As professoras especializadas têm formação inicial em Educação Especial ou uma de suas áreas, com complementação de estudos ou com pós-graduação em áreas específicas da Educação Especial. Perante esse documento legal, as atribuiçóes dessas profissionais náo se equivalem.

Todavia, a Política Nacional de Educação Especial na Perspectiva da Educação Inclusiva, "que orienta a oferta de cursos na linha da formaçẫo continuada de professores na área da Educação Especial é um dos movimentos que instituiu os Cursos de Atendimento Educacional Especializado ofertados em diferentes estados do Brasil" (SILUK, PAVÁO, 2014, p. 07), aciona o preparo para o acolhimento e o trato da diversidade. Diante dessa espécie de manejo ou traquejo didático, a referida Política Nacional intensifica a formação continuada das professoras, em detrimento da formação inicial, e produz, junto a esses cursos de aperfeiçoamento/extensão, a informação, a opinião, a generalização, a rapidez e o pragmatismo do atual serviço da Educação Especial. Instrumentalizar e tecnificar, através da formação continuada, a Educação Especial na inclusão como verdade contemporânea.

\title{
Tolerar, respeitar, solidarizar (ou pedagogizar a diversidade!)
}

\begin{abstract}
Ao iniciar o Curso Atendimento Educacional Especializado, muitas interrogaçóes motivaram meus estudos. De que forma posso mudar minha prática docente para favorecer a inclusão? Por onde começar? É viável pensar em inclusão? Como, quando e por onde começar? Quais apoios terei? Sou eu a responsável pela mudança de postura, diante de uma sociedade marcada pelas diferenças? Não há como negar que estamos constantemente enredados pela questão inclusiva. (MIRANDA, 2014, p. 129).
\end{abstract}

Questôes como essas do relato "A inclusão do deficiente mental em classe comum - um desafio a prática docente" cerceiam a vida das professoras e dizem sobre nossa relação com a diversidade. $\mathrm{O}$ direito à educação da diversidade parece inquestionável, mas o que fazemos com essa diversidade na sala da aula ou, no mesmo propósito, como fazemos para que a inclusão escolar dessa diversidade dê certo sempre? A questáo inclusiva, como menciona a cursista, faz parte de cada um de nós, e cada vez mais nos mobilizamos para produzir modos de sociabilidade ditos inclusivos na escola, na universidade, na sociedade. Isso ocorre, principalmente, com a emergência da articulação entre a Educação Especial e a Educação Inclusiva, na medida em que esta possibilita a continuidade, talvez eterna, da Pedagogia da Diversidade nas açóes escolares.

A Pedagogia da Diversidade que, desde as décadas de 60 e 70, trabalha com as reivindicaçóes dos grupos marginais ou minoritários, inclusive com as derivadas do público-alvo da Educação Especial, pode ser entendida no conjunto de tecnologias culturais, que "estão implicadas na produção de significados que dão às pessoas uma ideia de quem elas são e de quais serão seus futuros" (SIMON, 2002, p. 71). Essa tecnologia cultural, quando implicada com a escola contemporânea, projeta-a como 
espaço-tempo pluralista. Se antes pontuamos que cada um e todos têm direito à educação escolar no sistema regular de ensino, neste momento, com as contribuiçóes de Bhabha (1998), indicamos que a própria democracia, ao partir do princípio da igualdade, produz modos de sociabilidade pluralistas, portanto, inclusivos no jogo de cada um e todos.

E, justamente nesse jogo entre cada um e todos, a Pedagogia da Diversidade parte de uma identidade referencial para produzir permanentemente esse outro da diversidade. Nesse sentido, a Pedagogia da Diversidade, sob a tríade da tolerância, do respeito e da solidariedade, ocupa-se das práticas de normalização para produção desse sujeito "desde sempre aí" ou "para sempre aî". Neste artigo, interessam essas práticas de normalização presentes na materialidade analítica em questáo porque, de maneira expansiva e exaustiva, a formaçáo continuada de professoras em AEE na atual Rede Nacional de Formação de Professores na Educação Especial tem explorado um conjunto de diagnósticos, identificação, caracterização, classificação e hierarquização dos sujeitos da Educação Especial, e fixado formas da intervenção pedagógica para com esses sujeitos.

Considerando essa justificativa, a partir da leitura do currículo na perspectiva anglo-saxônica, entendemos que práticas curriculares tratam da "organização do ensino como um conjunto de atividades ou experiências organizadas segundo as atividades e experiências que se espera que as crianças desenvolvam na sua vida adulta" (NOGUERA-RAMÍREZ, 2011, p. 219), diferenciando-se da didática germânica e da ciência da educação francófona. Os relatos das professoras, perpassados tanto pela formação continuada quanto pelo exercício docente, uma vez que essas dimensóes complementam-se na docência, servem para demarcar o que estamos fazendo na escola dita inclusiva para produzir modos de sociabilidade inclusivos. Tolerar, respeitar e solidarizar constituem uma tríade porque, nesse conjunto de práticas curriculares, postulam a inclusão como verdade.

Portanto, nós, professores atuantes na Educação Especial, devemos ter como pressuposto que todos os alunos têm direito de estar juntos, convivendo e aprendendo (DOMINGOS, 2014, p. 52).

Do latim tolerare, a tolerância refere-se à capacidade humana de aceitar ou suportar, em diferentes gradientes, algum elemento contrário, diverso de si mesmo. Dessa forma, a escolarizaçáo da diversidade implica permitir ao outro que esteja junto conosco, sob o prisma mútuo da convivência e da aprendizagem, para que possamos incluir e otimizar nossas vidas nesse estar junto. Seja pela lógica do direito, como postula acima o fragmento do relato "A importância da formação para a qualidade da prática docente", seja pela prática propriamente dita com a diversidade, a operação entre um eu e um outro, nesses graus do aceitar ou do suportar, permite afirmar a identidade referencial, a medida comum, que serve como padrão de comparabilidade entre os ditos normais e o público-alvo da Educação Especial.

Dessa maneira, ao tomarmos esses gradientes derivados da tolerância, sendo que esta capacidade humana condiciona, de certa maneira, o conhecimento produzi- 
do sobre o sujeito da diversidade, interessa problematizar os modos como esse conhecimento provoca açóes de condução do público-alvo da Educação Especial na escola inclusiva. No Curso de Aperfeiçoamento/Extensão em Atendimento Educacional Especializado em questão, as cursistas relatam a organização dos módulos consoante à demarcação do conjunto de diagnósticos, identificação, caracterização, classificação e hierarquização dos sujeitos da Educação Especial e à consequente possibilidade de uma intervenção pedagógica. Exploremos o fragmento do relato "Uma pequena mudança para gerar um grande crescimento" a seguir:

Em resumo, todos os módulos priorizam primeiro o entendimento do que é a deficiência, o que ela abrange e como podemos visualizá-la, como trabalhar com ela, materiais disponíveis, se existe alguma lei que rege a deficiência e, por fim, prioriza o atendimento na visão de desenvolver o deficiente para que seja autossuficiente e sinta-se parte da sociedade, trazendo como participação especial a família, a escola regular e, como complemento, a sala de recursos com o AEE. (PAGLIARI, 2014, p. 115).

Primeiramente, os perfis do público-alvo da Educação Especial são priorizados nesses relatos. Focaliza-se o desvio e náo o sujeito. Esse desvio, portanto, passa a ser escrutinado dentro desse sistema que diagnostica, identifica, caracteriza, classifica e hierarquiza os sujeitos. Não estamos abordando a deficiência em cursos da área da saúde, mas, para tolerar, precisamos de um exame intencional e metódico no quadro do desvio. $\mathrm{O}$ ato de informar-se acerca de cada desvio pressupóe a possibilidade de gerenciar o risco na intervençáo pedagógica. Então, com informaçóes precisas, informaçôes estas que produzem determinados perfis desses sujeitos, essas cursistas podem planejar, ou recuperar planejamentos existentes no AEE, para desenvolver a intervenção na sala de recursos multifuncionais e nos demais espaços-tempos da escola.

A máxima foucaultiana de conhecer para governar parece fazer todo sentido nessa intervençáo pedagógica. O conhecimento, neste caso através da informaçáo, permite traçar os limites e as possibilidades dos sujeitos da diversidade. Para quê? Talvez, para que, na escolarização, esses sujeitos possam fazer parte da economia política da inclusão, esta que, em princípio, deseja transformar esses sujeitos em econômicos, maximizando os ganhos e minimizando as perdas nos processos de aprendizagem e desenvolvimento. Afinal, conhecer para governar movimenta essa conversa em torno da autonomia, da independência, da autossuficiência e da integraçáo na sociedade. Conversa, aliás, que não inicia na articulação da Educação Especial com a Educação Inclusiva, mas emerge com o projeto de uma Educaçáo Nacional no nosso país.

\begin{abstract}
Sabemos que o contexto educacional é composto pela diversidade, assim novas demandas se apresentam e a equipe escolar deve estar preparada para atender a todos os sujeitos com respeito e dignidade. Dessa forma, a qualificação para que o atendimento ocorra com qualidade é uma necessidade. (GUILHERME, 2014, p. 55).
\end{abstract}

Esse fragmento pertence aos relato "A importância da formação para a qualidade da prática docente". Trata, entre outros elementos, do respeito. Do latim respectus, essa noção implica olhar para trás e valorizar. Parece, dentre as outras - tolerar e solidarizar -, ser a noção de um dos sentimentos mais positivos frente à diversidade. 
Pois bem, essa noção está presente neste relato e em muitos outros relatos. Contudo, respeitar não significa deixar de normalizar. O AEE com qualidade refere-se, imanentemente, às práticas de normalização. Aqui, vale ressaltar a positividade na leitura dessas práticas de normalização, na medida em que a constituição de sujeitos da aprendizagem pressupóe a circularidade da norma nessas práticas, bem como a produção de sujeitos mais normais possíveis diante da identidade referencial.

Dessa forma, para cada diverso e para os diversos no todo da diversidade, respeitados em suas condiçóes digamos, será necessário dizer, no campo da Educação Especial, o que funciona e o que náo serve para esses sujeitos. Os objetivos e os procedimentos didático-pedagógicos, as adaptaçóes curriculares, as práticas alternativas, as avaliaçóes de desempenho e idade, entre outros, estão nesse conjunto de práticas que funcionam pretensamente no AEE. Com isso, tratar dos sujeitos da diversidade na Educação Especial significa coloca-los diante de uma identidade referencial e, num padrão de comparabilidade, produzir atributos diferenciais nas práticas de normalização na escola dita inclusiva. $\mathrm{O}$ direito, a diversidade e a pluralidade não apagam essas práticas, pelo contrário, intensificam-as quando, ao olhar para trás e valorizar, potencializam uma forma de ser sujeito.

Sei que preciso de muita formação, informação, mas também de atuação, pois só a prática me permitirá a busca por um ideal e não apenas pelo óbvio proposto. Tenho buscado firmar parceria com as famílias, com a escola e toda comunidade escolar. Educação é uma relação amorosa. É preciso apaixonar-se no ato. Estou me apaixonando! Vejo como fantástica a possibilidade de ainda reunir ensino e afetividade. Tenho certeza que náo à toa denominaram como especial cada ser que nasce com o cromossomo do amor triplicado. (LUZ, 2014, p. 64).

Por fim, solidarizar. Considerada uma virtude cristã durante muito tempo, tal noção diz respeito ao vínculo, à relação mútua entre sujeitos. Atualmente, podemos inscrevê-la no contexto da governamentalidade neoliberal. Os sujeitos desta escola dita inclusiva relacionam-se à prática governamental, ou seja, precisam fazer a inclusáo escolar dar certo para os sujeitos da diversidade, para os que com eles relacionam-se. Nesse sentido, o fragmento do relato "Prática da professora da sala de recursos multifuncional" mobiliza o envolvimento das professoras do AEE com as famílias, os demais profissionais, a comunidade escolar, etc., para tornar a inclusão possível. Mais do que uma obrigatoriedade legal, a inclusáo coloca-se como um princípio desses sujeitos na escola dita inclusiva.

Dessa maneira, como diria o primeiro fragmento, "é preciso apaixonar-se no ato". A inclusão escolar faz de cada um de nós um agente, um articulador, um multiplicador das suas açóes. Colaboração, parceria e solidariedade fazem parte desse contexto no qual a escola dita inclusiva, como uma unidade-empresa, une todos em torno dos mesmos objetivos e dos mesmos fins. Dito de outra maneira, trata-se de produzir modos de sociabilidade plurais, inclusivos nessa escola. Alguém pode náo se apaixonar no ato? Seria talvez arriscado, no mínimo ousado, dizer que sim. A racionalidade política em questão, a partir da Pedagogia da Diversidade, trabalha em prol 
da massificação dos sujeitos nesses espaços-tempos de inclusão. $\mathrm{O}$ cromossomo do amor triplicado precisa, se já não está conosco, desenvolver-se imperativamente para ser e estar professora na escola dita inclusiva.

Do direito à educação da diversidade à Pedagogia da Diversidade; da celebração à pedagogização da diversidade, efetivamos um exercício de problematização em torno de como a Pedagogia da Diversidade tem perpassado a formaçáo continuada das professoras na Rede Nacional de Formação Continuada de Professores na Educação Especial, e as práticas curriculares ditas inclusivas na escola contemporânea. Através da tríade da tolerância, do respeito e da solidariedade, essa formaçáo continuada e essas práticas curriculares produzem, através das práticas de normalizaçáo, modos de sociabilidade plurais, inclusivos no registro da governamentalidade neoliberal. Nesse contexto, materializaram-se os imperativos deste exercício de problematizaçáo: Celebrar a diversidade! Exaltar a tolerância! Notabilizar o respeito! Proclamar a solidariedade!

\section{Referências}

BRASIL. Conselho Nacional de Educação. Conselho Pleno. Resolução CNE/CP no 2, de 01 de junho de 2015, Diretrizes Curriculares Nacionais para a Formaçáo Inicial em Nível Superior (cursos de licenciatura, cursos de formaçáo pedagógica para graduados e cursos de segunda licenciatura) e para a Formaçáo Continuada. Instituto Latino-Americano de Planejamento Educacional. Disponível em: <http://www.ilape.edu.br/ instrumentos-de-avaliacao/doc_download/778-resolucao-cne-cp-2-2015-define-as-diretrizes-curriculares-para -os-cursos-de-licenciatura-e-formacao-pedagogica-para-formacao-continuada>. Acesso em: 06 jul. 2015.

Conselho Nacional de Educação. Câmara de Educação Básica. Resolução no 2, de 11 de setembro de 2001. Institui Diretrizes Curriculares Nacionais para a Educação Especial na Educaçáo Básica. Diário Oficial [da] República Federativa do Brasil, Brasília, DF, 14 set. 2001. Disponível em: <http://pesquisa.in.gov. $\mathrm{br} /$ imprensa/jsp/visualiza/index.jsp?data $=14 / 09 / 2001 \&$ jornal=1\&pagina $=39 \&$ totalArquivos $=204>$. Acesso em: 13 set. 2013.

Constituiçáo da República Federativa do Brasil de 1988. Disponível em: http://www.planalto.gov. br/ccivil_03/constituicao/constituicaocompilado.htm. Acesso em: 24 jun. 2015.

Lei $\mathbf{n}^{\circ}$ 8.069, de 13 de julho de 1990. Dispốe sobre o Estatuto da Criança e do Adolescente e dá outras providências. Disponível em: <http://www.planalto.gov.br/ccivil_03/LEIS/L8069.htm>. Acesso em: 24 jun. 2015.

Lei de Diretrizes e Bases da Educaçáo Nacional.Lei no 9394, de 20 de dezembro de 1996. Estabelece diretrizes e bases da Educação Nacional. Diário Oficial [da] República Federativa do Brasil, Brasília, DF, 23 dez. 1996. Disponível em: <http://www.planalto.gov.br/ccivil_03/leis/L9394.htm>. Acesso em: 19 jan. 2015.

Ministério da Educação. Secretaria de Educação Especial. Política Nacional de Educação Especial na Perspectiva da Educação Inclusiva. In: Inclusão: Revista da Educação Especial, Brasília, v. 04, n. 01, p. 09-17, jan./jun. 2008.

COELHO, A. V. Relato 14. AEE para o autismo infantil. In: SILUK, A. C. P.; PAVÃO, S. M. O. (Orgs.). Atendimento Educacional Especializado no Brasil: relatos da experiência profissional de professores e sua formaçấo. $1^{\text {a }}$ Ed. Santa Maria: Universidade Federal de Santa Maria, Centro de Educação, Laboratório de Pesquisa e Documentação, 2014, p. 106-110.

CONVENÇĀO DE GUATEMALA. In: Decreto no 3.956, de 8 de outubro de 2001. Promulga a Convenção Interamericana para a Eliminaçấo de Todas as Formas de Discriminação contra as Pessoas Portadoras de Deficiência. Disponível em: <http://www.planalto.gov.br/ccivil_03/decreto/2001/d3956.htm>. Acesso em 01 abr. 2015.

DECLARAÇÃO DE SALAMANCA - SOBRE PRINCÍPIOS, POLÍTICAS E PRÁTICAS EM EDUCAÇÃO ESPEÇAAL. In: BLATTES, R. L. (Org.). Direito à educação: subsídios para a gestão dos sistemas educacionais: orientaçōes gerais e marcos legais. 2a Ed. Brasília: MEC, SEESP, 2006, p. 328-343. 
DECLARAÇÃO DOS DIREITOS DAS PESSOAS DEFICIENTES. Disponível em: <http://portal.mec.gov. br/seesp/arquivos/pdf/dec_def.pdf>. Acesso em 01 abr. 2015.

DECLARAÇÃO MUNDIAL SOBRE EDUCAÇÃO PARA TODOS - SATISFAÇÓES DAS NECESSIDADES BÁSICAS DE APRENDIZAGEM. In: BRASIL. Plano Decenal de Educaçáo para Todos. Brasília: MEC, 1993, p. 67-81.

DOMINGOS, A. R. F. S. Relato 5. O AEE sob o olhar de uma técnica em Educação Especial da Secretaria Municipal de Educação. In: SILUK, A. C. P.; PAVÃO, S. M. O. (Orgs.). Atendimento Educacional Especializado no Brasil: relatos da experiência profissional de professores e sua formação. $1^{\text {a }}$ Ed. Santa Maria: Universidade Federal de Santa Maria, Centro de Educação, Laboratório de Pesquisa e Documentação, 2014, p. 48-53.

FOUCAULT, M. Segurança, território e populaçáo. Curso dado no Collège de France (1977-1978). Tradução de Eduardo Brandão. São Paulo: Martins Fontes, 2008a. 572 p. (Coleção tópicos)

Nascimento da biopolítica. Curso dado no Collège de France (1978-1979). Tradução de Eduardo Brandão. São Paulo: Martins Fontes, 2008b. 474 p. (Coleçấo tópicos)

GONÇALVES, A. T. Relato 3. Perspectiva de sucesso para o aprendizado da pessoa com necessidades educacionais especiais. In: SILUK, A. C. P.; PAVÃO, S. M. O. (Orgs.). Atendimento Educacional Especializado no Brasil: relatos da experiência profissional de professores e sua formaçáo. $1^{\text {a }}$ Ed. Santa Maria: Universidade Federal de Santa Maria, Centro de Educação, Laboratório de Pesquisa e Documentação, 2014, p. 38-41.

GUILHERME, J. D. P. Relato 6. A importância da formação para a qualidade da prática docente. In: SILUK, A. C. P.; PAVÃO, S. M. O. (Orgs.). Atendimento Educacional Especializado no Brasil: relatos da experiência profissional de professores e sua formação. $1^{\text {a }}$ Ed. Santa Maria: Universidade Federal de Santa Maria, Centro de Educação, Laboratório de Pesquisa e Documentação, 2014, p. 54-58.

KARSTEDT, A. C. Relato 11. Aplicabilidade do Curso AEE: desenvolvimento da autonomia. In: SILUK, A. C. P.; PAVÃO, S. M. O. (Orgs.). Atendimento Educacional Especializado no Brasil: relatos da experiência profissional de professores e sua formação. $1^{\text {a }}$ Ed. Santa Maria: Universidade Federal de Santa Maria, Centro de Educação, Laboratório de Pesquisa e Documentação, 2014, p. 86-92.

LUZ, C. C. S. Relato 7. Prática da professora da sala de recursos multifuncional. In: SILUK, A. C. P.; PAVÁO, S. M. O. (Orgs.). Atendimento Educacional Especializado no Brasil: relatos da experiência profissional de professores e sua formação. $1^{\text {a }}$ Ed. Santa Maria: Universidade Federal de Santa Maria, Centro de Educação, Laboratório de Pesquisa e Documentação, 2014, p. 60-64.

MIRANDA, A. A. Relato 18. A inclusão do deficiente mental em classe comum - Um desafio à prática docente. In: SILUK, A. C. P.; PAVÃO, S. M. O. (Orgs.). Atendimento Educacional Especializado no Brasil: relatos da experiência profissional de professores e sua formaçấo. 1 ${ }^{\mathrm{a}}$ Ed. Santa Maria: Universidade Federal de Santa Maria, Centro de Educação, Laboratório de Pesquisa e Documentação, 2014, p. 128-135.

OLIVEIRA, C. G. Relato 24. Aplicabilidade do Curso de AEE: o movimento da Educaçáo Inclusiva. In: SILUK, A. C. P.; PAVÃO, S. M. O. (Orgs.). Atendimento Educacional Especializado no Brasil: relatos da experiência profissional de professores e sua formação. 1ª Ed. Santa Maria: Universidade Federal de Santa Maria, Centro de Educação, Laboratório de Pesquisa e Documentação, 2014, p. 166-172.

PAGLIARI, D. C. Relato 15. Uma pequena mudança para gerar um grande crescimento. In: SILUK, A. C. P.; PAVÃO, S. M. O. (Orgs.). Atendimento Educacional Especializado no Brasil: relatos da experiência profissional de professores e sua formaçáo. $1^{\text {a }}$ Ed. Santa Maria: Universidade Federal de Santa Maria, Centro de Educação, Laboratório de Pesquisa e Documentação, 2014, p. 112-117.

SANTOS, C. M. M. Relato 20. Curso AEE: viabilizando o trabalho em equipe. In: SILUK, A. C. P.; PAVÃO, S. M. O. (Orgs.). Atendimento Educacional Especializado no Brasil: relatos da experiência profissional de professores e sua formação. $1^{a}$ Ed. Santa Maria: Universidade Federal de Santa Maria, Centro de Educação, Laboratório de Pesquisa e Documentação, 2014, p. 140-147.

NOGUERA-RAMÍREZ, C. E. Pedagogia e governamentalidade ou da modernidade como uma sociedade educativa. Belo Horizonte: Autêntica Editora, 2011. 268 p. (Coleção Estudos Foucaultianos)

SILUK, A. C. P.; PAVÃO, S. M. O. (Orgs.). Atendimento Educacional Especializado no Brasil: relatos da experiência profissional de professores e sua formação. Santa Maria: UFSM, CE, Laboratório de Pesquisa e Documentação, 2014. 175 p.

SIMON, R. I. A pedagogia como uma tecnologia cultural. In: SILVA, T. T. (Org.). Alienígenas na sala de aula: uma introdução aos Estudos Culturais em Educação. Petrópolis: Vozes, 2002, p. 61-84. 
Márcia Lise Lunardi-Lazzarin - Simoni Timm Hermes

\section{Correspondência}

Márcia Lise Lunardi-Lazzarin - Universidade Federal de Santa Maria, Centro de Educação. Faixa Camobi, Km9 - Campus Universitário - Prédio 16, Camobi. CEP: 97105-900 - Santa Maria, RS - Brasil.

E-mail: lunazza@gmail.com - simoni.hermes@ufsm.br

Recebido em 14 de junho de 2015

Aprovado em 06 de agosto de 2015 